\title{
Sujeitos com deficiência no mundo do trabalho: discursos que marcam aparências e, por sua vez, capacidades?
}

\author{
Subjects with disabilities in the world of work: speeches that show \\ appearances and, in turn, abilities?
}

Sujetos con discapacidad en el mundo del trabajo: discursos que marcan apariencias y, a su vez, capacidades?

\section{Silvana Matos Uhmann}

Professora doutora na Universidade Federal Fluminense, Angra dos Reis, Rio de Janeiro, Brasil. silvana_uhmann@id.uff.br

ORCID - https://orcid.org/0000-0003-1182-3187

\section{Maria Simone Vione Schwengber}

Professora doutora pela Universidade Regional do Noroeste do Estado do Rio Grande do Sul, ljuí, Rio Grande do Sul, Brasil.

simone@unijui.edu.br

ORCID - https://orcid.org/0000-0002-3583-1408

Recebido em 20 de maio 2018

Aprovado em 9 de junho de 2020

Publicado em 8 de julho de 2020

\section{RESUMO}

O tema do trabalho relacionado aos sujeitos com deficiência permite realizar problematizações com relação às marcas de diferença inscritas em seus corpos, e que, por sua vez, dão a possibilidade de discutir sobre discursos de aparências e capacidades desses sujeitos. Ao considerar que o mundo do trabalho traz a possibilidade de subjetivações através de experiências positivas e/ou negativas, é que fazemos a seguinte pergunta de pesquisa: Como os corpos marcados pela deficiência são percebidos no mundo do trabalho? Este artigo tem como objetivo problematizar o tema da inserção de pessoas com deficiência no mercado do trabalho a fim de perceber quais são os discursos que tencionam este processo. Como metodologia, sob a perspectiva foucaultiana e da análise do discurso, apresentamos imagens previamente selecionadas na web, de autoria de Ricardo Ferraz, para exemplificar experiências de trabalho que pode ser vivenciada por uma pessoa com deficiência física (cadeirante). Os resultados possibilitam pensar nos impasses que muitas vezes vivenciam as pessoas com deficiência dentro do mercado de trabalho, sendo percebidas muitas vezes pela ideia de falta, anormalidade, bem como relacionando à aparência de deficiência a limitações de suas capacidades. Como possibilidades destacamos o discurso midiático como instituinte de possíveis novos e encorajados comportamentos por formadores de opinião, ao somar ao discurso social que resiste em não aceitar funções menos qualificadas aos sujeitos que ocupam as cotas.

Palavras-chave: Pessoa com deficiência; mundo do trabalho; Educação Especial.

\section{ABSTRACT}

The theme of work related to subjects with disabilities allows problematization with respect to the marks of difference inscribed on their bodies, which, in turn, give the possibility to 
http://dx.doi.org/10.5902/1984686X32843

discuss speeches about the appearance and capabilities of these subjects. When considering that the world of work brings the possibility of subjectivations through positive and/or negative experiences, we ask the following research question: How are bodies marked by disability perceived in the world of work? This article aims to discuss the issue of the insertion of people with disabilities in the labor market in order to understand what are the discourses that intend this process. As a methodology, from a Foucauldian perspective and discourse analysis, we present images previously selected on the web, by Ricardo Ferraz, to exemplify work experiences that can be experienced by a person with physical disability (wheelchair). The results make it possible to think about the impasses that people with disabilities often experience within the labor market, being often perceived by the idea of lack, abnormality, as well as relating the appearance of disability to the limitations of their abilities. As possibilities, we highlight the media discourse as the instigator of possible new and encouraged behaviors by opinion makers, adding to the social discourse that resists not accepting less qualified functions to the subjects that occupy the quotas.

Keywords: People with disabilities; world of works; Special Education.

\section{RESUMEN}

El tema del trabajo relacionado con sujetos con discapacidad permite la problematización con respecto a las marcas de diferencia inscritas en sus cuerpos, lo que, a su vez, brinda la posibilidad de discutir discursos sobre la apariencia y las capacidades de estos sujetos. Cuando consideramos que el mundo del trabajo brinda la posibilidad de subjetivaciones a través de experiencias positivas y/o negativas, hacemos la siguiente pregunta de investigación: ¿Cómo se perciben los cuerpos marcados por la discapacidad en el mundo del trabajo? Este artículo tiene como objetivo discutir el tema de la inserción de personas con discapacidad en el mercado laboral para comprender cuáles son los discursos que pretenden este proceso. Como metodología, desde una perspectiva foucaultiana y análisis del discurso, presentamos imágenes previamente seleccionadas en la web, por Ricardo Ferraz, para ejemplificar las experiencias laborales que puede experimentar una persona con discapacidad física (silla de ruedas). Los resultados permiten pensar en los callejones sin salida que las personas con discapacidad a menudo experimentan en el mercado laboral, siendo percibidos a menudo por la idea de falta, anormalidad, así como relacionando la apariencia de discapacidad con las limitaciones de sus capacidades. Destacamos las posibilidades del discurso mediático como el instigador de posibles comportamientos nuevos y alentados por parte de los creadores de opinión, que se suman al discurso social que se resiste a no aceptar funciones menos calificadas para los sujetos que ocupan las cuotas.

Palabras clave: Persona con discapacidad; mundo del trabajo; Educación Especial.

\section{Introdução}

A inclusão dos sujeitos com deficiência é um tema que está inserido em quase todos os meios sociais, sendo o mundo do trabalho recorte deste artigo. Ao reconhecermos o trabalho como uma forma de interação com o meio e entre as pessoas, destacamos a possibilidade de o trabalho subjetivar e constituir os sujeitos de acordo com suas práticas e experiências. E, para além disso, o espaço do trabalho vem ocupando destaque em 
http://dx.doi.org/10.5902/1984686X32843

pesquisas e discussões à medida que estabelece a possibilidade de inclusão e/ou exclusão das pessoas com deficiência.

O termo subjetivação, de acordo com Foucault (2004), refere-se ao modo como o próprio humano compreende-se ou torna-se/modifica-se por meio das relações. Nisso, entendemos o sujeito, segundo Foucault (2004), através de uma prática de autoformação do mesmo. Em outras palavras, consideramos que o trabalho é um espaço que exerce as dimensões de subjetivar e constituir os sujeitos, o que diante das pessoas com deficiência irá acontecer por meio de práticas inclusivas ou excludentes. Com isso, destacamos a importância do trabalho para os sujeitos com deficiência, pois representa a possibilidade de proporcionar aprendizagens, relações, transformação de conceitos e atitudes, aprimoramento, remuneração e, sobretudo, torna-se um espaço importante para as dimensões de subjetivação.

Neste sentido, podemos considerar alguns avanços na busca pela garantia de direitos das pessoas com deficiência para o trabalho, representada pela Lei de Cotas nํ 8.213/91, a qual estabelece cota mínima de contratação de pessoas com deficiência: a empresa com 100 (cem) ou mais empregados está obrigada a preencher de $2 \%$ (dois por cento) a $5 \%$ (cinco por cento) dos seus cargos com beneficiários reabilitados ou pessoas com deficiência, na seguinte proporção: I - até 200 empregados - 2\%; II - de 201 a 500 - 3\%; III - de 501 a 1000 - 4\%; IV - de 1001 em diante - 5\% (BRASIL, 1991). Vale ressaltar que, segundo o artigo 93ำ da mesma Lei, há determinação de cotas mínimas, podendo a empresa contratar um número maior de pessoas com deficiência.

É evidente que se trata de um avanço para a inserção dos sujeitos com deficiência no mundo de trabalho, mas entendemos que a existência da Lei muitas vezes não é garantia de efetivação, uma vez que as pessoas com deficiência foram por muito tempo consideradas incapazes, ou seja, pessoas que não correspondiam aos parâmetros de exigência para inserirem-se no mercado de trabalho (ARANHA, 2001). Romper com tais entendimentos não é tarefa fácil e, ao que parece, os sujeitos com deficiência podem obter experiências positivas, mas também negativas em relação ao trabalho.

É seguindo estas ideias que este artigo tem como objetivo problematizar o tema da inclusão de pessoas com deficiência no mundo do trabalho, a fim de perceber alguns dos discursos que podem compor este processo. Isso porque concebemos o trabalho a partir de experiências de inclusão ou não, as quais merecem nossa atenção e compreensão. 
http://dx.doi.org/10.5902/1984686X32843

Para entender os discursos que podem compor esse processo, fazemos a seguinte pergunta: Como os corpos marcados pela deficiência são percebidos no espaço no mundo do trabalho? Alguns autores Omote (2014); Greiner (2005); Louro (2004); Skiliar (2003) ajudam-nos pensar que as marcas inscritas nos corpos dos sujeitos com deficiência têm efeitos nas relações sociais estabelecidas, e estas, por sua vez, têm a possibilidade de conceder legitimação (ou não) dos sujeitos com deficiência. Trata-se de algo que não está aquém do trabalho, mas o consideramos espaço fértil de subjetivar e constituir os sujeitos. Nosso interesse é perceber como estas questões dão-se no mundo do trabalho e, para isso, a seguir destacamos os caminhos metodológicos para realizar essa discussão.

\section{Metodologia}

Ao entender que a presente temática merece destaque, optamos por apresentar imagens que nos ajudam pensar a experiência das pessoas com deficiência no mundo do trabalho. Este recurso ajuda-nos problematizar a inserção desses sujeitos sob a ótica das representações discursivas a que podem estar submetidos ao longo de suas vivências e experiências no trabalho.

Para tanto, optamos por pensar as imagens do colunista Ricardo Ferraz, o qual apresenta ilustrações que caracterizam as pessoas com deficiência em diferentes situações do dia a dia, denunciando e problematizando a condição da diferença. Optamos por este ilustrador e colunista, pois tem grande parte de sua trajetória envolvida com a inclusão em diferentes espaços sociais, apresentando muitas vezes com ironia e sofrimento o cotidiano das pessoas com deficiência. A partir da seleção de três imagens, dentre tantas de autoria de Ricardo, buscaremos entender os enunciados desenhados, bem como os discursos que apresentam a relação entre o trabalho e os sujeitos com deficiência.

É nas ideias de Foucault (1987) que pensamos nos enunciados presentes em discursos. O conceito de discurso, em Foucault (1987), não se trata de uma simples expressão de ideias, mas falar segundo determinadas regras, práticas, relações e entendimentos que se dão dentro de um discurso, que por sua vez é histórico e mutável.

Utilizaremos nesta pesquisa aspectos metodológicos sugeridos por Fischer (2001), a partir das contribuições de Foucault (1987) diante da Análise de Discurso. Fischer (2001) esclarece: compreender os enunciados em seus discursos implica dar conta de um referente (princípio de diferenciação), de um sujeito (no sentido de 'posição' a ser ocupada), de um campo associado (isto é, coexistir com outros enunciados) e de uma materialidade 
http://dx.doi.org/10.5902/1984686X32843

específica (por tratar de coisas efetivamente ditas, escritas, gravadas em algum tipo de material, passíveis de repetição ou reprodução, ativadas através de técnicas, práticas e relações sociais). Tais aspectos aproximam a pesquisa na perspectiva foucaultiana de discurso, a qual é:

[...] é fugir das explicações de ordem ideológica, das teorias conspiratórias da história, de explicações mecanicistas de todo tipo: é dar conta de como nos tornamos sujeitos de certos discursos, de como certas verdades se tornam naturais, hegemônicas, especialmente de como certas verdades se transformam em verdades para cada sujeito. (FISCHER, 2003, p. 385-386).

Nossa intenção, ao utilizar tal abordagem, é qualificar o campo de discussões da inclusão das pessoas com deficiência no mundo do trabalho, propondo reflexões sobre situações reais e que merecem nossa atenção não apenas para o que está dito, mas suas relações, entendimentos, aquilo que Foucault (1987) também definiu como não dito, mas que também subjetivam e constituem as pessoas com deficiência. Seguindo essas ideias, trazemos imagens como forma de problematização pois as entendemos como possíveis de suscitar discussões sobre a condição de deficiência (representado através de pessoas com deficiência física) dentro da perspectiva da inserção no contexto do trabalho.

\section{Problematizando a deficiência no mundo do trabalho: o acesso}

Figura 1 - Acesso da pessoa com deficiência no mundo do trabalho

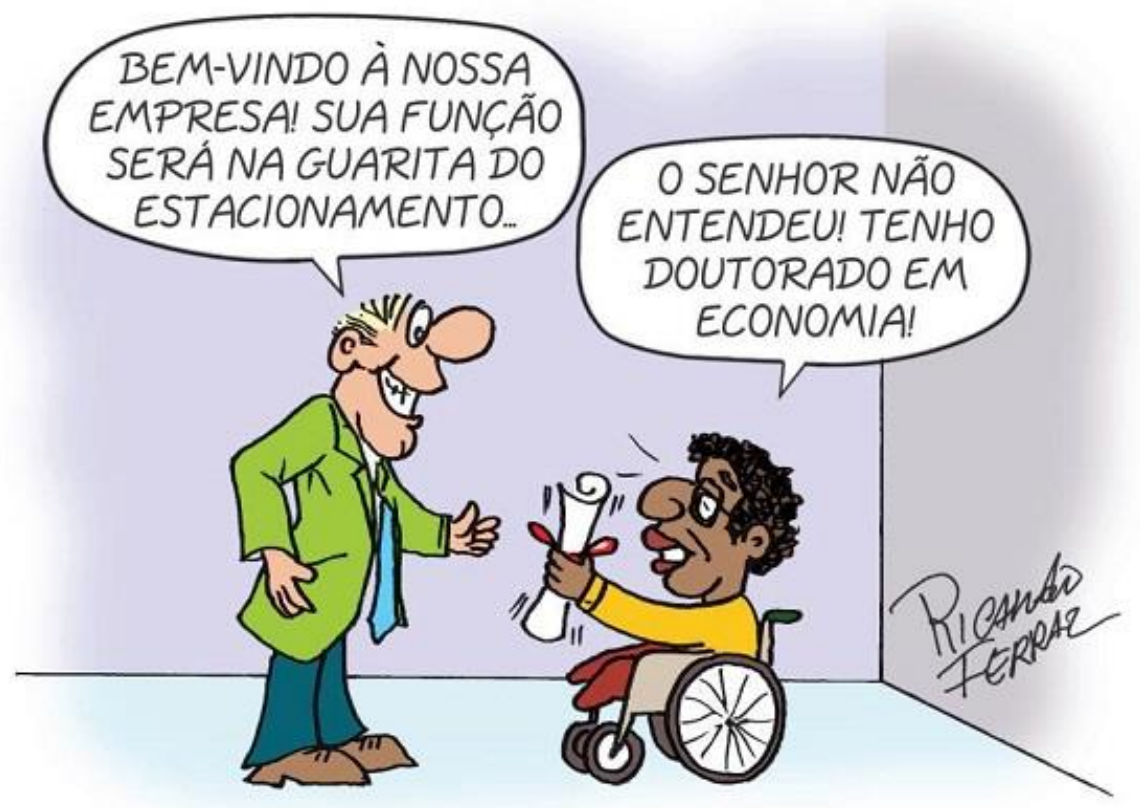

Fonte: http://www.deficienteciente.com.br/entrevista-com-o-cartunista-ricardo-ferraz.html. 
http://dx.doi.org/10.5902/1984686X32843

O acesso das pessoas com deficiência no mundo do trabalho ainda representa muitos impasses, mas, mesmo assim, trazem como fator a importância e o sentido que o trabalho emerge na vida dessas pessoas (LIMA; TAVARES; BRITO; CAPPELLE, 2013). O trabalho é reconhecido como um meio em que pessoas com deficiência podem demonstrar suas competências e habilidades, ser reconhecidas profissionalmente diante do sentimento de contribuição para a sociedade, além do contato com colegas, pertencimento ao grupo, expansão de redes sociais e, consequentemente, redução de situações de exclusão.

Para adentrar nessa discussão, iniciamos apresentando uma imagem que faz menção a isto, na condição de, poderia se dizer, uma entrevista de emprego - buscando reflexões sobre o acesso das pessoas com deficiência no mercado de trabalho. Interessa-nos problematizá-la visto que entendemos o fato de estar ali na discursividade e na condição de uma pessoa com deficiência buscando uma vaga de emprego, podendo ser realidade de muitas pessoas que utilizam as cotas como forma de acesso.

Problematizamos de início que o acesso da pessoa com deficiência ao mundo do trabalho passa pela dimensão do corpo, pois é ele que, de antemão, permite-nos perceber a condição de ser diferente a partir das marcas presentes nos corpos, pois exprime os aspectos visíveis da diferença como a falta de um braço, perna, malformação. Os corpos, portanto, passam a ter papel central a medida que inscrito neles, as diferenças apresentamse como:

[...] um arcabouço para os processos de subjetivação, a trajetória para se chegar ao "ser" (...). A constituição do ser humano, como um tipo específico de sujeito, ou seja, subjetivado de determinada maneira, só é possível pelo "caminho" do corpo. (MENDES, 2006, p. 168).

Seguindo essas ideias, Veiga-Neto (2001) demarca o corpo como um lugar com possibilidade de demarcar anormalidades, patologias, incapacidades, deficiências. Importa perceber os discursos sobre os corpos incorretos: demasiado pequeno ou demasiado grande; demasiado gordo ou demasiado magro; não suficiente masculino ou suficiente feminino; com ou sem deficiência. É o corpo que, justamente em nossa primeira imagem, traz o enunciado de deficiência, representado pela pessoa com deficiência física que solicita emprego.

Em princípio, visualizamos uma cena que retrata um diálogo entre uma pessoa com deficiência física na condição de solicitar emprego e outro sujeito na posição de chefe demonstrando estar satisfeito em recebê-lo. A imagem apresenta o chefe na condição de 
http://dx.doi.org/10.5902/1984686X32843

branco, alto, loiro, superior, e o empregado (ou aquele que ainda busca o emprego) como cadeirante, negro, e parece-nos um tanto preocupado. A organização associa-se ao princípio de inclusão de pessoas com deficiência, considerando-se inclusiva por conceder a estes sujeitos a possibilidade do exercício de funções dentro de empresas - algo representando pelo sorriso do chefe recebendo a pessoa com deficiência.

Tal responsabilidade social é firmada na palavra do chefe que, por sua vez, exprime vários discursos éticos/sociais sobre a inclusão de pessoas com deficiência: Bem-vindo à nossa empresa! No entanto, o que nos interessa discursivamente vem a seguir: Sua função será na guarita do estacionamento. Percebemos que há o anúncio pelo chefe do local de trabalho do cadeirante antes mesmo de ouvir dele sua atuação/formação. Aqui nos perguntamos: por que é destinada de antemão esta função ao cadeirante? Tal questionamento está presente na expressão do cadeirante que logo explica: $O$ senhor não entendeu! Tenho doutorado em economia! Percebemos a pessoa com deficiência física através de uma expressão de indignação (discurso de exclamação!) e que, com a mão, apresenta seu diploma a fim de comprovar sua formação e explicar-se como alguém investido e com qualificação profissional.

Logo, a questão que parece estar em jogo: Qual a credibilidade dada a um doutorado quando se trata de um cadeirante? Adentramos em um campo discursivo que apresenta a pessoa com deficiência muitas vezes tendo passado pela escola sem o mesmo rendimento de uma pessoa sem deficiência, sendo "passada de ano" - algo que, consequentemente, estenderia-se até chegar ao doutorado. Assim, é possível reconhecer um campo discursivo que fixa limitações como centralidade e discursivamente sobressaem-se às possíveis competências desses sujeitos. Mesmo não sendo únicos (mas talvez ainda os de maior potência), tais discursos, encharcados de limitações, muitas vezes definem pouca credibilidade ao doutorado de uma pessoa com deficiência, levando à generalização.

Ao receber uma pessoa com deficiência buscando alguma vaga de emprego, pouca credibilidade e oportunidades são a ela (e possivelmente a todas) concedidas. Neste sentido, a posição do chefe considerou o cadeirante sem, ou pouca formação, e que por isso logo definiu: Sua função na guarita do estacionamento. Na imagem parece haver o imperativo de inferioridade, visto que o chefe, de cima para baixo, destina ao novo funcionário o lugar que irá ocupar, já havendo como conclusão um sujeito que não possui escolarização, logo, com capacidades limitadas. Ao cadeirante, resta sentimentos de subestimação, indignação, tensionamento. 
http://dx.doi.org/10.5902/1984686X32843

Ainda, outros aspectos podem ser apontados: a imagem mostra o diálogo acontecendo em um espaço que dá a ideia de um lugar retirado, e não do escritório da empresa, em que se discutem e acontecem geralmente as situações importantes. Isso porque, ao que parece, o chefe foi apenas comunicar o local de trabalho da pessoa com deficiência - fato que talvez não considerou de importância.

O que nos instiga é justamente a certeza do chefe de que o cadeirante fosse trabalhar na guarita do estacionamento sem antes saber dele seus conhecimentos, currículo, formação. Mas, o que leva o chefe agir desta forma? E, ao saber do doutorado, sua compreensão/atitude seria modificada? Ao que parece, a deficiência inscrita em seu corpo incute sobre os sujeitos com deficiência a ideia da necessidade de exercer atividades muitas vezes inferiores das que possuem condições - o que possivelmente poderia permanecer mesmo sabendo da existência de diploma com qualificação profissional, já que ao tratar-se de pessoas com deficiência, este nem sempre é sinônimo de reconhecimento.

Então, o que é visto? A imagem apresenta enunciados e discursos que revelam um contexto em que o sujeito com deficiência parece posicioná-lo na condição de menoridade, inferioridade, tudo inscrito em seu corpo. Trata-se de uma pessoa visivelmente marcada pela deficiência e que não a esconde: é deficiente físico, cadeirante, amputado. Tais características parecem conceder a ele pouca convicção das outras pessoas sobre suas capacidades que o legitimam através do merecimento de um emprego menos importante. A imagem, sobretudo, apresenta a inclusão no mundo do trabalho de uma pessoa com deficiência, mas ainda com tensionamentos devido à sua aparência entre a atividade que merece exercer e aquela que é a ela destinada. Em outras palavras, as cotas podem contribuir para o acesso ao mercado de trabalho, mas não sobre o reconhecimento de suas funções/formação.

Com isso, podemos pensar que a ideia de acesso ao trabalho ligado aos sujeitos com deficiência pode, na maioria das vezes, direcionar-se para atividades manuais, não tão complexas e/ou importantes. Isso porque a estas pessoas são conferidos entendimentos e discursos que tomam como ponto de partida a deficiência entendida como barreira, empecilho, dificuldade. A estes sujeitos, a caridade de conceder um emprego o coloca em um lugar menor do que muitas vezes poderia estar.

Nestes discursos, a imagem denuncia a condição de ser cadeirante já colocando o sujeito com deficiência como inferior e, mesmo não considerando a guarita do estacionamento como cargo ruim de trabalho, não está de acordo com sua formação de 
doutorado em economia que, de antemão, foi a ele destinada. É como se a condição de ser pessoa com deficiência chegasse primeiro que o próprio sujeito, e estipulasse a ele formas de ver e ser visto pelas demais pessoas.

Tal imagem ainda faz refletir: Qual é a condição social e intelectual de uma sociedade quando há doutores em busca de emprego? Se ainda muito reclamamos do analfabetismo funcional de jovens, qual o estranhamento de doutores desempregados? De qual mercado de trabalho estamos falando? Tratam-se de questionamentos importantes que pensamos ser pano de fundo de nossas discussões, já que problematizam, segundo o referencial foucaltiano, o quanto os funcionários de uma empresa estão como peças na engrenagem para cumprir funções e não necessariamente para pensá-las.

\section{Problematizando a deficiência no mundo do trabalho: a permanência}

Figura 2 - Permanência da pessoa com deficiência no mundo do trabalho

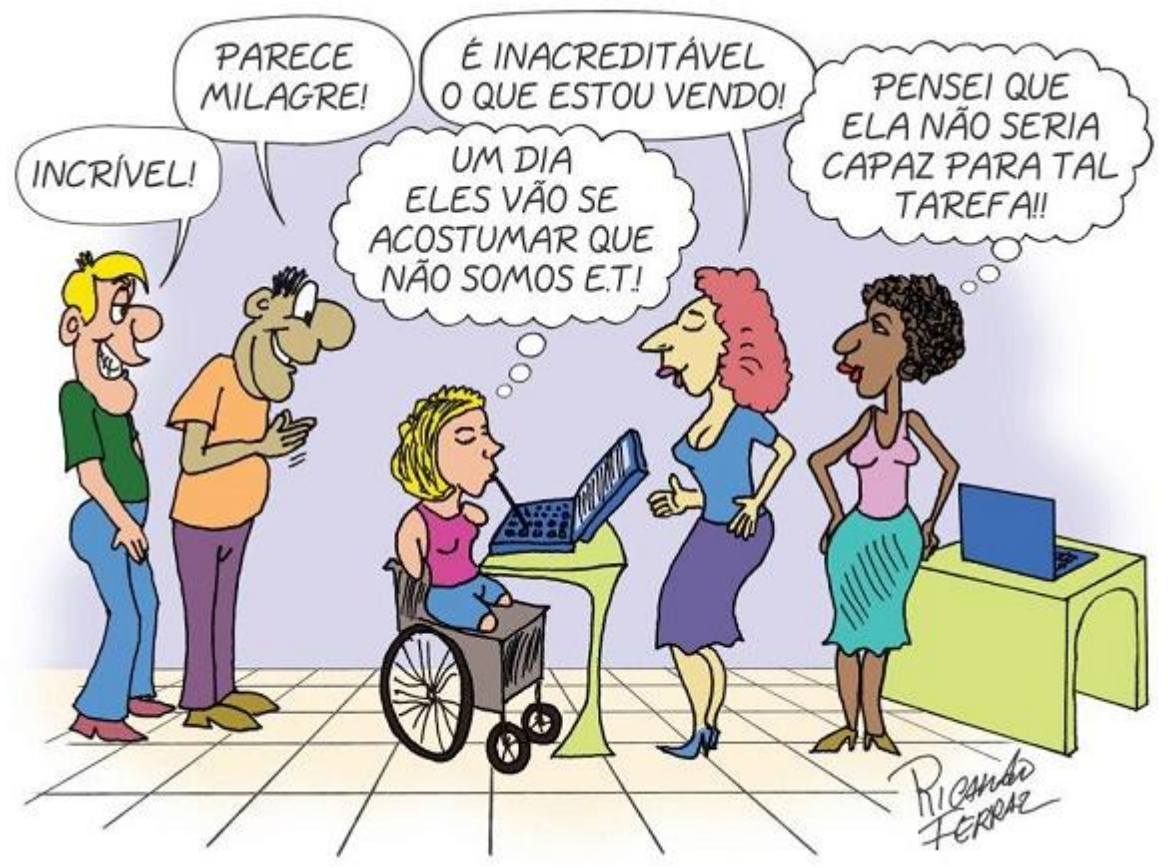

Fonte: https://www.deficienteciente.com.br/entrevista-com-o-cartunista-ricardo-ferraz.html.

A permanência das pessoas com deficiência no mundo do trabalho também merece ser problematizada, uma vez que não basta conceder oportunidade de acesso, mas preocupar-se com suas condições de permanência. Escolhemos apresentar uma imagem que caracteriza o que muitas pessoas com deficiência vivenciam no trabalho com relação à falta de conhecimento sobre as capacidades para o exercício do trabalho. Em outras palavras, é concedido o acesso à pessoa com deficiência ao trabalho, mas sua 
http://dx.doi.org/10.5902/1984686X32843

permanência é marcada por desconhecimento e/ou pouco acreditar em suas potencialidades/habilidades.

Diante disso, precisamos considerar que ao longo do desenvolvimento humano, algumas diferenças foram interpretadas como desvio, passíveis de temor e também de desconfiança: "condições como por exemplo aberrações cromossômicas, erros metabólicos, lesões do sistema nervoso central, malformações variadas, etc. acarretam, frequentemente, essas diferenças" (OMOTE, 2014, p.20). Sendo assim, algumas características marcadas no corpo podem chamar especial atenção - não se comunicar com o auxílio da fala, a necessidade de cadeira de rodas para locomoção, óculos e bengala para cegos, movimentos estereotipados, membros corporais disformes.

A imagem acima bem representa estas ideias: há uma pessoa cadeirante sem braços e pernas desenvolvendo algum trabalho profissionalmente a despertar olhares curiosos, duvidosos, incrédulos. Ao seu redor, há pessoas que a observam e consideram a tarefa por ela realizada: Incrível; Parece milagre; É inacreditável o que estou vendo. É como se nunca esperassem que alguém com deficiência física pudesse realizar tal tarefa - que na imagem aparece escrevendo com a boca. Há outra pessoa ao seu lado que na imagem ocupa um papel sarcástico: Pensei que ela não seria capaz para tal tarefa. A cena demonstra a ausência de entendimento sobre a deficiência ou, mais do que isso, o entendimento errôneo sobre estas pessoas, limitador, incapacitado.

Em contrapartida, a imagem apresenta a pessoa cadeirante dizendo: Um dia eles vão se acostumar que não somos ET, ao perceber os olhares e discursos sobre si e suas ações. “Um dia eles vão se acostumar que não somos ET'- aproxima-se a uma prece religiosa ou cheia de esperança e mostra o quanto haveria de se esperar para que uma mudança no jeito de pensar e receber pessoas diferentes de si poderia levar. Isso leva-nos a problematizar o poder os discursos (FOUCAULT, 2004) que imperam sobre as pessoas com deficiência no mundo do trabalho que, historicamente, parecem vir subjetivando os sujeitos através de saberes que os colocam como inferiores à espera de uma mudança

É possível destacar também o estranhamento ao uso de aparelhos/tecnologias que não do modo convencional. Aqui, cabe a reflexão: O quanto apenas consumimos tecnologias e não as pensamos como um meio diferente do usual? É possível problematizar a falta de informação em sociedade sobre tecnologias/aparelhos, sobretudo destinado às pessoas com deficiência, o que contribui para discursos de preconceito e limitadores destinados a estas pessoas. Em específico sobre a imagem acima, é importante destacar 
http://dx.doi.org/10.5902/1984686X32843

o recurso midiático de formação de opinião mediante à denúncia da desinformação sobre estes recursos, apresentando-se como um campo importante de disseminação de informações sobre as pessoas com deficiência no mundo do trabalho.

Mundo do trabalho que, definitivamente, não garante efetividade de ações apenas pela existência das cotas. Reconhecemos que, se as ações afirmativas não existissem, a desigualdade seria ainda mais acentuada, contudo, o acesso e a permanência de pessoas com deficiência precisa ser constantemente problematizados, uma vez que a permanência das pessoas com deficiência pode estar submersa à muitas situações: Algumas empresas promovem a formação da equipe de colegas do novo funcionário e outras empresas ofertam todos períodos de formação voltados à inclusão de novos comportamentos e atitudes, enquanto outras empresas ainda não estenderam para além do mínimo necessário a cumprir a legislação apenas. Questionamos: O quanto os novos funcionários participam dessa formação? Há nos departamentos de Recursos Humanos/Desenvolvimento Pessoal pessoas capacitadas a esses treinamentos? Como estas formações acontecem e o quanto possibilitam efetivamente condições para inclusão de trabalhadores com alguma deficiência?

Tais questionamentos, a nosso entender, precisam evidenciar a compreensão de pessoa com deficiência, bem como suas possibilidades e discursos ainda limitadores. Diante disso, é imprescindível, mais uma vez, problematizarmos que muitas vezes é no corpo que as deficiências apresentam-se, geralmente associadas à fragilidade humana, pois podem ser percebidos sobre ele traços atípicos. As marcas corporais impressas nos corpos dos sujeitos com deficiência são a porta de entrada para apresentações, sendo que Louro (2004, p. 75) ajuda a pensar o quanto "a determinação dos lugares sociais, das posições dos sujeitos no interior de um grupo é referida a seus corpos".

É como se houvessem holofotes (no sentido de luz) sob as marcas corporais de deficiência, concedendo a esses sujeitos o lugar que Skliar (2003, p.41) denominou de $O$ Outro, o qual "pode ser pensado sempre como exterioridade, como alguma coisa que eu não sou, que nós não somos". Desta forma: "há, então, um outro que nos é próximo, que parece ser compreensível para nós, previsível, maleável. E há um outro que nos é distante, que parece ser incompreensível, imprevisível" (SKLIAR, 2003, p.41).

Segundo o mesmo autor, ao Outro distante - o qual pode ser problematizado a partir da cadeirante e amputada da imagem acima - há geralmente uma imagem colonial, quer dizer, a imagem de um Outro maléfico, que não é compreendido, nem aceito: "O outro 
http://dx.doi.org/10.5902/1984686X32843

colonial e maléfico é um corpo sem corpo. Uma voz que fala sem voz. Que diz sem dizer. Que foi massacrado e segue sendo culpabilizado por seu próprio massacre (SKLIAR, 2003, p. 41). Trata-se de: "Uma repressão do outro que gira em torno de um eu completo, natural, concêntrico, onisciente, disseminado, Todo-Poderoso" (SKLIAR, 2003, p.42).

Percebe-se com isso o normal e o anormal, o deficiente e o não deficiente, quem marca corporalmente uma deficiência e quem passa despercebido. Para a cadeirante e amputada da imagem, sob o seu corpo há o imperativo de incapacidade ligado à falta dos braços e pernas, à necessidade de cadeira de rodas. Mas, quando demonstra realizar tarefas sem dificuldades e muitas vezes iguais às pessoas que possuem estes membros ou não utilizam cadeira de rodas, colocam em cheque os entendimentos ultrapassados e limitantes da deficiência.

Bauman (1998, p. 14), este contexto, explica a ordem como uma preocupação moderna: "cada coisa se acha no seu justo lugar e não em qualquer outro". Para o autor, a modernidade é entendida pela tentativa obsessiva de classificar os sujeitos, em que o sonho da pureza não se dá longe dessa ordem, dessa norma. O oposto estaria do lado de fora e é por Bauman (1998) denominado de estranho, que rompe com a ideia de normalidade. $O$ estranho entendido como corporificação de sujeira trás a ideia de que o mundo perfeito era "um mundo transparente [...] em que nada estragasse a harmonia; nada fora do lugar; um mundo sem sujeira; um mundo sem estranhos" (BAUMANN, 1998, p .21), um mundo sem refugo.

No entanto, o mesmo autor reconhece: "os estranhos [...] estão aqui para ficar" (BAUMANN, 1998, p.43). O Outro (anormal, estranho) vem como uma perturbação da mesmice que, nas palavras de Skliar (2003, p. 44): "irrompe, e nessa irrupção, nossa mesmice vê-se desamparada, destituída de sua corporalidade homogênea, de seu egoísmo". É como se os ideais de normalidade já não fizessem tanto sentido, abrindo caminhos para ter outros entendimentos, olhar para os sujeitos com deficiência com outros olhos, não mais como anormais e/ou estranhos, mas como possibilidade de diferença.

A questão definitivamente não é mais como livrar-se dos estranhos, dos anormais, dos Outros que já vêm conquistando espaços no mundo do trabalho, mas preocupar-se com a sua permanência. Nisso é importante entender que as pessoas com deficiência muitas vezes são percebidas através da falta de um braço, da falta de audição, da falta de visão, da necessidade da utilização de cadeira de rodas. Pensar os sujeitos com deficiência a partir de suas marcas corporais é também falar de seus corpos deficientes e suas marcas 
http://dx.doi.org/10.5902/1984686X32843

ligadas ao afastamento das normas estabelecidas por determinada normalização. Falar de um corpo que é considerado deficiente é também falar de seus estigmas, de seu ocultamento, dos olhares a ele dirigidos, ou seja, a visibilidade desviante apresentada por seus corpos. Goffman (1993) apresenta a noção de estigma como marca ou sinal incutido às pessoas que se afastam da idealização de perfeição. Como exemplo: uma perna amputada ou ainda a presença - necessidade de cadeira de rodas, enfim, o que estiver inscrito no corpo e que visivelmente demonstre anormalidade, é entendido e considerado inaceitável aos olhos da normalidade.

A falta de entendimento sobre as capacidades dos sujeitos com deficiência pode apresentar-se como um dos motivos que impedem ou limitam as contratações deste público-alvo pelas empresas ou, quando há contratação, condução de funções que não condizem com suas formações. Por isso, pensamos ser importante problematizar os discursos sobre a deficiência, definitivamente não sob a aparência de ser deficiente, mas pelas potencialidades que não deixa de ter em função de sua condição.

\section{Buscando concluir e problematizar a deficiência no mercado de trabalho: discursos que marcam aparências e, por sua vez, capacidades?}

Iniciamos nossas ideias considerando os impasses ainda vivenciados pelos sujeitos com deficiência nos diferentes espaços sociais, sendo o mundo do trabalho nosso recorte neste artigo. Há relativamente pouco tempo as pessoas com deficiência começaram a ocupar o campo do trabalho, pois, à exigência da inclusão através de leis e políticas públicas, as empresas viram-se obrigadas a contratá-los. Entretanto, o que nos inquietou desde o primeiro momento foi justamente problematizar como esses sujeitos estão inseridos no mundo do trabalho.

Ao que parece, há uma centralidade diante do corpo da pessoa com deficiência, uma vez que sobre ele são inscritas características que constituem aparências e, a partir delas, os enunciados e discursos parecem estabelecer-se. Assim:

No caso das pessoas com deficiência, suas diferenças ganham conotações importantes e, como num eco, reverberam sob a forma de preconceitos que banalizam suas potencialidades. Tais pessoas costumam ser percebidas pelo que lhes falta, pelo que necessitam em termos assistenciais e não pelo seu potencial latente e que exige oportunidades para manifestação e desenvolvimento. (CARVALHO, 2010, p.17). 
http://dx.doi.org/10.5902/1984686X32843

Isso porque o conceito de deficiência muitas vezes parece estar amarrado à ideia de dificuldade/anormalidade, e nisso corre o risco de permanecer à margem de espaços sociais, sendo estigmatizados por discursos e práticas que não correspondem às pessoas com deficiência - o que pode ser problematizado nas duas imagens analisadas e relacionadas ao mundo do trabalho.

A normalidade, como observamos na primeira imagem, é caracterizada o mais próximo possível do chefe: andante, saudável, branco, competente, líder da empresa. Dentro desta lógica, não andar com as pernas e também não ser de cor branca parece conferir ao sujeito ocupar um lugar inferior à sua capacidade. Já, na segunda imagem, a normalidade pode ser representada longe da amputação de membros e uso de cadeira de rodas. Em outras palavras, há uma normatização que rege ocupar um ou outro espaço, sobretudo disposta à existência da deficiência expressa pelo corpo que, na imagem de cadeirante/amputado, permanece cristalizada no imaginário social trabalhador/operário condicionante.

Muitas vezes, a deficiência conduz a uma posição de assujeitamento que, segundo Foucault (1987), determina relações entre os sujeitos e, por sua vez, são responsáveis pela constituição destes mesmos sujeitos, comprometendo tanto o acesso como a permanência destas pessoas no mundo do trabalho. É importante destacar os impasses/dificuldades frente aos sujeitos com deficiência,

[...] pois não sabem ao certo que função ou cargo irão ocupar, oferecem algo incompatível com as habilidades apresentadas pelos deficientes ou dão-lhes funções nas quais desempenham ações repetitivas sem significados para eles. Outro aspecto importante é a preparação dos colaboradores para receber essa população, pois, em algumas pesquisas a discriminação e ou afastamento dos deficientes por parte dos colegas de trabalho é fato marcante no cotidiano dessas pessoas, é preciso também a criação de ferramentas que facilitem o trabalho dos deficientes para o bom desempenho de suas funções. A falta de informação por parte das empresas prejudica ambos os lados. (NASCIMENTO, 2006, p.8).

Assim, torna-se importante destacar que as pessoas com deficiência podem muitas vezes ser posicionadas em graus inferiores dentro do trabalho, contribuindo para 0 entendimento de que possuem poucas capacidades. Contudo, a primeira imagem que utilizamos apresenta uma pessoa com deficiência física com o título de Doutor, fato que contribui para a reflexão de que a condição de deficiência não o torna incapaz de também atingir um alto nível de escolarização. Em outras palavras, como na segunda imagem, 
http://dx.doi.org/10.5902/1984686X32843

realizar tarefas até então consideradas possíveis apenas para quem não apresenta deficiência.

Entretanto, não raro, os sujeitos com deficiência muitas vezes são tratados com inferiores, incapacitados e infantis, marcados por um curto sentimentalismo em função do que Ihes falta, os empobrece, os deixa feios, marcados, estereotipados. Nesse sentido, o corpo deficiente pode ser entendido como um lugar de exclusão social (LOURO, 2004), ou seja, à margem estariam os sujeitos que não apresentam características constituídas e consideradas normais. Os sujeitos nesse caso são produzidos pela incapacidade e em nome de um processo inclusivo que impera nos dias de hoje, o mais natural é ocupar outros lugares, outras posições que não aquelas de pessoas sem deficiência. Mais natural seria permanecerem na guarita do estacionamento, ou apresentar diversas dificuldades em escrever com a boca.

A inserção e permanência no mundo do trabalho importa para o sujeito com deficiência como uma forma de incluir-se na sociedade e interagir com ela. Tais discursos estão presentes, por exemplo, nas áreas dos direitos humanos, legislações e políticas públicas, no sentido de avançar e buscar consolidar direitos das pessoas com deficiência. No entanto, pensamos que a inclusão dos sujeitos com deficiência no mundo do trabalho não traz apenas contribuições para os próprios sujeitos, mas beneficiam as empresas através de experiências de sensibilização, empatia, respeito e reconhecimento da diferença.

Entendemos que o reconhecimento da inserção dos sujeitos com deficiência no mundo do trabalho não pode estar apenas ligado à existência da lei de cotas para este público-alvo. O que pensamos ser necessário são discursos cada vez menos carregados de preconceito de que a deficiência conduz a problemas ou incapacidades para assumir as funções exigidas diante de seu trabalho - o que, a partir desse trabalho, pode ser problematizado pela mídia. Em outras palavras, a escolha e problematização de discursos midiáticos podem somar ao discurso social que resiste em não aceitar funções menos qualificadas aos sujeitos que ocupam as cotas.

Sabemos que estas mudanças exigem da sociedade como um todo e, sobretudo, dos espaços empresariais um novo entendimento e postura das empresas e seus membros sobre acessibilidade e empregabilidade sob o mundo do trabalho. Por isso, não basta apenas conceder espaços para que as pessoas com deficiência sejam integrantes/membros de empresas, precisamos estar atentos aos enunciados que os rodeiam que, como produtores desses discursos, nós possuímos papéis centrais nestas 
http://dx.doi.org/10.5902/1984686X32843

mudanças. Tensionar tais discursos é um pouco o movimento deste texto, o qual nos inquieta e também pensamos poder inquietar outras pessoas. Assim, a pergunta Discursos que marcam aparências e, por sua vez, capacidades? apresentou através das imagens deste texto a deficiência física inscrita sob o corpo e, a partir dela, definiram-se pelas demais pessoas no espaço do trabalho algumas capacidades ou, a falta delas às pessoas com deficiência.

Estamos convencidas de que sim, os discursos marcam a aparência e, por sua vez, a capacidade. Marcam, pois, à medida em que possuem traços de diferença inscritas sob os corpos, esta aparência traz consigo representações de anormalidade. E entendemos que essa condição pode ser considerada ainda o grande entrave e o que ocasiona os tensionamentos dia a dia dos sujeitos com deficiência no mundo do trabalho.

Contudo, pensamos a mídia como potência a contribuir nas discussões, ao problematizá-las por meio das imagens utilizadas, trazendo novos e encorajados comportamentos por formadores de opinião (as vezes pouco utilizadas ou ainda consideradas menos populares) - mais voltada às capacidades das pessoas com deficiência que, definitivamente, não precisam estar ligadas às limitações existentes. As imagens de Ricardo Ferraz apresentam um horizonte a ser reconhecido e explorado que não se finalizam em suas representações, mas que possibilitam tensionar discursos existentes e propor outros, sobretudo por meio do estímulo e valorização das mídias sobre as capacidades das pessoas com deficiência.

Ao reconhecer que as mídias são um conjunto de diferentes meios de comunicação, com a finalidade de transmitir informações e conteúdos variados, acreditamos que seriam um importante meio de transmissão de informações sobre as pessoas com deficiência, não apenas no campo do trabalho, mas em diferentes espações/aspectos. Em outras palavras, trata-se de informações preocupadas em desmistificar preconceitos quanto às limitações da deficiência e ao conhecimento de suas capacidades no espaço do trabalho, algo que passa a somar ao discurso social que resiste em não aceitar funções menos qualificadas aos sujeitos que ocupam as cotas.

A inclusão não se limita apenas a sua contratação à empresa/trabalho. É importante perceber o acesso, mas sobretudo a sua permanência - e para isso, por exemplo, destacamos a fiscalização das empresas quanto ao cumprimento da Lei, levar em consideração a sensibilização da empresa e colaboradores, bem como adaptações organizacionais, funcionais e práticas para uma melhor adaptação da pessoa com 
deficiência à equipe e vice-versa impedindo que haja evasão ou abandono devido à falta de condições de trabalho. Ou ainda, formações à equipe para compreender a deficiência para além de fatores limitadores - em que a mídia poderia auxiliar na elaboração e transmissão dessas informações as empresas, famílias, bem como sociedade em geral. Acreditamos que os discursos midiáticos podem contribuir na reflexão e problematização da (d)eficiência, fixando deficiência não como contrário de eficiência: o contrário de eficiência é a ineficiência, e não as pessoas com deficiência. Sobretudo, percebemos os discursos midiáticos como importante instrumento para potencializar, trazer informações e dar visibilidade a inserção de pessoas com deficiência no mercado de trabalho proativa e, não somente, definitivamente, por obrigatoriedade legal.

\section{Referências}

ARANHA, Maria Salete Fábio. Integração Social do Deficiente: Análise Conceitual e Metodológica. 1. ed. Ribeirão Preto: Sociedade Brasileira de Psicologia, 2001.

BAUMAN, Zygmunt. O Mal-estar da pós-Modernidade. 2. ed. Rio de Janeiro: Jorge Zahar, 1998.

BRASIL. Diário Oficial [da] República Federativa do Brasil, Poder Executivo. Lei de Cotas no. 8213: Dispõe sobre os Planos de Benefícios da Previdência Social e dá outras providências. Brasília, DF, 1991.53p.

CARVALHO, Rosita Edler. Escola inclusiva: a reorganização do trabalho pedagógico. 2. ed. Porto Alegre: Mediação, 2010.

FISCHER, Rosa Maria Bueno. Foucault e a análise do discurso em educação. Cadernos de Pesquisa, São Paulo, n. 1, p. 197-223, nov. 2001.

FISCHER, Rosa Maria Bueno. Foucault revoluciona a pesquisa em educação?.

Perspectiva, Florianópolis, n. 2, p. 371-389, jul./dez, 2003.

FOUCAULT, Michel. Vigiar e punir: nascimento da prisão. 2. ed. Petrópolis: Vozes, 2004.

FOUCAULT, Michel. História da sexualidade: o uso dos prazeres. 1. ed. Rio de Janeiro: Graal, 1987.

GOFFMAN, Erving. Estigma: la identidad deteriorada. 1. ed. Buenos Aires: Amorrortu, 1993.

GREINER, Christine. O corpo: pistas para estudos indisciplinares. 1. ed. São Paulo: Annablume, 2005. 
LIMA, Michelle Pinto de; TAVARES, Nathália Vasconcelos; BRITO, Mozar José de; CAPPELLE, Mônica Carvalho Alves. O sentido do trabalho para pessoas com deficiência. Revista de Administração Mackenzie, v. 14, n. 2, p. 42-68, 2013.

LOURO, Guacira Lopes. Um corpo estranho: ensaios sobre sexualidade e teoria queer. 1. ed. Belo Horizonte: Autêntica, 2004.

MENDES, Eniceia Gonçalves. Perspectivas atuais da educação inclusiva no Brasil. In: ANAIS DO III ENCONTRO DE EDUCAÇÃO ESPECIAL DA UEM. 2006, Maringá. Anais... Maringá: Editora UEM, 2006. p. 15-35.

NASCIMENTO, Eliane de Souza. A educação e o encaminhamento para o trabalho das pessoas com deficiência. In: ANAIS do 18을 EPENN - Encontro de Pesquisa Educacional do Norte e Nordeste. 2006, Maceió. Anais... Maceió: Universidade Federal de Alagoas, 2006. p. 78-93.

OMOTE, Sadão. Aparência e competência: uma relação a ser considerada na educação especial. 1. ed. Curitiba: Appris, 2014.

SKLIAR, Carlos. Pedagogia improvável da diferença: e se o outro não estivesse aí? 1. ed. Rio de Janeiro: DP\&A, 2003.

VEIGA-NETO, Alfredo. Incluir para excluir. In: LARROSSA, Jorge. \& SKLIAR, Carlos. (org). Habitantes de Babel: políticas e poéticas da diferença. Belo Horizonte: Autêntica, 2001. p. 105-118.

\section{Correspondência}

Silvana Matos Uhmann - Universidade Federal Fluminense, Av. dos Trabalhadores, $\mathrm{n}$. 179, Verolme, Angra dos Reis, Rio Janeiro - Brasil.

CEP: $23914-360$

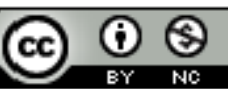

This work is licensed under a Creative Commons Attribution-NonCommercial 4.0 International (CC BY-NC 4.0) 